\title{
Cuidar de crianças autistas: experiências de familiares
}

\author{
Caring for autist children: family experiences \\ Cuidando a los niños autores: experiencias familiares
}

Jairo Caique de Araújo $^{1 *}$, Aisiane Cedraz Morais ${ }^{1}$, Mayane Trindade da Silva ${ }^{1}$, Rita da Cruz Amorim ${ }^{1}$, Sinara Lima Souza ${ }^{1}$.

\section{RESUMO}

Objetivo: Analisar como os familiares cuidam de crianças com autismo. Métodos: Estudo qualitativo, descritivo e exploratório, realizado no Centro de Atenção Psicossocial infanto-juvenil, no interior da Bahia. Participaram desse estudo, nove familiares de crianças autistas em 2018, a coleta utilizou-se entrevista e os resultados foram avaliados por Análise de Conteúdo. Resultados: A sobrecarga materna evidenciou-se nesse contexto, pois a rotina se apresenta com carga estressante, alta demanda de cuidados, como rotina, alimentação, estimulação especializada, atenção em outros ambientes sociais e situações envolvendo dependência dos filhos, abdicação de vida social e profissional, atrelado a ausência de apoio dos pais das crianças. Conclusão: Após confirmação do autismo, a família vivencia uma variedade de sentimentos, há alterações de relações e, e em maiores escalas, predisposição ao estigma social, fator que acaba limitando a autonomia da criança e vivência social/profissional da mãe que assume os cuidados do filho.

Palavras-chave: Cuidado da criança, Transtorno do espectro autista, Família.

\section{ABSTRACT}

Objective: To analyze how family members take care of children with autism. Method: This is a qualitative, descriptive and exploratory study, conducted at the Center for Psychosocial Care for children and adolescents, in the interior of Bahia. Nine relatives of autistic children participated in this study in 2018. The collection used an interview and the results were evaluated by Content Analysis. Results: Maternal overload was evident in this context, as the routine is stressful, high demand for care, such as routine, feeding, specialized stimulation, attention in other social environments and situations involving dependence on children, abdication of social and professional life, linked to the lack of support from the children's parents. Conclusions: After confirmation of autism, the family experiences a variety of feelings, there are changes in relationships and, on larger scales, predisposition to social stigma, a factor that ends up limiting the child's autonomy and social / professional experience of the mother who takes care of the child.

Key words: ChildCare, Autism spectrum disorder, Family.

\section{RESUMEN}

Objetivo: Analizar cómo los miembros de la familia cuidan a los niños con autismo. Metodología: se trata de un estudio cualitativo, descriptivo y exploratorio, realizado en el Centro de Atención Psicosocial Infantil, en el interior de Bahia. Nueve familiares de niños autistas participaron en este estudio en 2018, la colección utilizó una entrevista y los resultados fueron evaluados por Análisis de Contenido. Resultados: La sobrecarga materna fue evidente en este contexto, ya que la rutina es estresante, una alta demanda de atención, como la rutina, la alimentación, la estimulación especializada, la atención em otros entornos sociales y las situaciones que implican la dependencia de los niños, la abdicación de la vida social y Profesional, vinculado a la falta de apoyo de los padres de los niños. Conclusiones: Después de la confirmación del autismo, la familia experimenta una variedad de sentimientos, hay cambios en las relaciones y, en escalas más grandes, predisposición al estigma social, un factor que termina limitando la autonomía del niño y la experiencia social / profesional de la madre que cuida del hijo.

Palabras clave: Cuidado infantil, Trastorno del espectro autista, Familia.

1 Universidade Estadual de Feira de Santana (UEFS), Feira de Santana - BA.

*E-mail: caiquearaujoenf@gmail.com

SUBMETIDO EM: 10/2019 


\section{INTRODUÇÃO}

Atualmente estima-se que no mundo, a cada 88 crianças nascidas vidas, uma seja diagnosticada com TEA, e esta prevalência acomete em maiores proporções o sexo masculino. Há teorias que indicam o motivo desta diferença dos meninos, como por exemplo: por possuírem córtex cerebral mais fino, altos níveis de testosterona fetal, mutação do gene ligado ao cromossomo $X$, além da facilidade de finalizar o diagnóstico entre meninos em virtude de maior clareza e gravidade na apresentação dos sintomas (INSTITUTO LK, 2018). Além disso, em 2010 foi estimado um total de 500 mil pessoas com autismo no Brasil, ressaltando ainda a subnotificação de tal condição em virtude da falta de dados sobre os diagnósticos exatos, clareza nas definições e tempo no processo de observação dessas crianças (GOMES PTM, et al., 2015).

O Transtorno do Espectro Autista é um agravo crônico, compreendido como o grupo de alterações que geram déficit no desenvolvimento cognitivo associado a habilidades sociais, comunicativas e comportamentais. Esses sinais clínicos são manifestados antes dos 36 meses de idade e são mais demonstrados no âmbito das relações sociais (MAIA FA, et al., 2016).

A etiopatogenia não está elucidada completamente, porém, há estudos que comprovam a forte relação multifatorial, entre aspectos genéticos (alterações cromossômicas, microdelações/microduplicações, doenças monogênicas) e ambientais (exposição a agentes tóxicos durante a gestação como talidomida, misoprostol e ácido válpróico, mães com mais de 35 anos, baixo peso ao nascer, asfixia perinatal, infecções perinatais) (LYALL K et al., 2014; BRASIL, 2014).

O diagnóstico geralmente é consolidado por volta do terceiro ano, mas as manifestações clínicas (choro indiferenciado, grito excessivo, não responsividade a gestos, pouco interesse por brincadeiras/jogos lúdicos, atenção a partes de brinquedo do que sua própria função, ecolalia, isolamento, desinteresse e rejeição a brincar com outras crianças, recusa alimentar) são perceptíveis previamente, porém os critérios diagnósticos nem sempre são observados de forma clara na assistência (JOZÉFCZUK J, et al., 2017).

Assim, teve como questão de investigação: como os familiares cuidam de crianças com transtorno do espectro autista? Essa problemática parte da inquietação por entender os cuidados prestados pelas famílias às crianças, quais as vivências destas, bem como conhecer qual a rede de suporte social para esse cuidado cotidiano. Além disso, foi percebido a pouca abordagem sobre a temática durante a graduação em enfermagem, e posteriormente, contribuir com a discussão deste tema no espaço acadêmico e profissional. Por isso, tem-se como objetivo geral: analisar como os familiares cuidam de crianças com TEA; e como objetivos específicos: descrever os cuidados direcionados às crianças com TEA pelos familiares; identificar os aspectos que interferem no cuidar de crianças com autismo e descrever a rede de suporte social para 0 cuidado com crianças com TEA.

\section{MÉTODOS}

Trata-se de um estudo qualitativo, descritivo e exploratório. Esta pesquisa foi desenvolvida em um município do estado da Bahia, sendo o campo de coleta um Centro de Atenção Psicossocial infanto-juvenil. Os participantes desse estudo foram 9 familiares de crianças diagnosticadas com transtorno do espectro autista que eram atendidos neste serviço, selecionados de forma aleatória, sendo coletados dados até ser evidenciado a saturação de informações colhidas.

Utilizou-se os seguintes critérios de inclusão: ser familiar de crianças de três a dez (3-10) anos, que tenham o diagnóstico de TEA há pelo menos 1 ano, considerando esse um tempo mínimo para incorporação de rotinas de cuidado. Ressalta-se que não foram excluídas do estudo aquelas que convivam com crianças com TEA que apresentem comorbidades, uma vez que esta associação está em torno de $71 \%$. Para inclusão, o participante deveria aceitar participar voluntariamente da pesquisa, assinar o Termo de Consentimento Livre e Esclarecido (TCLE) e concordar que sua entrevista fosse gravada.

A técnica empregada para a coleta de dados desse estudo foi entrevista semiestruturada. Utilizou-se os seguintes pontos: 1) Entendimento sobre o transtorno do espectro autista; 2) Como é para você cuidar do seu 
filho? 3) Quais são os cuidados que você tem com seu filho? 4) Com quem você conta para auxiliar no cuidado do seu filho? Durante a entrevista, foram coletados alguns dados sócio-demográficos dos familiares e crianças, que permitiram a compressão de aspectos relacionados ao processo cuidar/cuidado. Esta pesquisa foi aprovada pelo Comitê de Ética em Pesquisa/UEFS (C.A.A.E. no 2.800.742). Neste estudo, foram utilizados nomes próprios (pseudônimos) aleatórios, escolhidos pelos pesquisadores para preservar a identidade e confidencialidade dos entrevistados.

\section{RESULTADOS E DISCUSSÃO}

Os resultados que emergiram da análise foram ordenados em três categorias, sendo: 1) Familiares/cuidadores das crianças autistas: quem são? 2) Do (des) conhecimento do autismo ao diagnóstico; 3) Cuidado ao filho autista: rotina e sobrecarga materna e 4) Rede de suporte ou exclusão social?

\section{Familiares/cuidadores das crianças das crianças autistas}

Os 9 familiares inseridos na pesquisa são em sua totalidade são as mães de tais crianças, onde eram os familiares que acompanhavam estas crianças até o serviço de saúde. Essas mães tinham idade de 31 a 50 anos; a maioria (4 participantes) se identificou apenas como cristã por não ter uma religião específica, seguido de católicas (3 participantes) e protestantes (2 participantes). Entre as mães, cinco (5) eram solteiras e as outras (4) eram casadas. Com relação à convivência familiar, encontramos quatro (4) mães moravam apenas com seus filhos, três (3) conviviam com os maridos e filhos e duas (2) moravam como seus pais e filhos e sem os maridos, o que demonstram diferentes arranjos familiares. Entre as mães, seis (6) auto declaravamse pardas/negras e três (3) como brancas. Quanto à escolaridade, quatro (4) possuem ensino médio completo, seguido de duas (2) tem ensino fundamental incompleto, uma (1) tem ensino fundamental completo, uma (1) tinha ensino superior incompleto e apenas uma (1) tinha ensino superior completo.

Quadro 1 - Caracterização dos familiares

\begin{tabular}{|c|c|c|c|c|c|c|c|c|}
\hline Familiares & Idade & $\begin{array}{c}\text { Raça/ } \\
\text { cor }\end{array}$ & Escolaridade & $\begin{array}{c}\text { Estado } \\
\text { Civil }\end{array}$ & Religião & Ocupação & $\begin{array}{l}\text { № de } \\
\text { filhos }\end{array}$ & $\begin{array}{c}\text { Com quem } \\
\text { mora }\end{array}$ \\
\hline Entrevistada 1 & 39 & Parda & $\begin{array}{l}\text { Ensino Méd. } \\
\text { Completo }\end{array}$ & Solteira & Católica & $\begin{array}{c}\text { Dona de } \\
\text { casa }\end{array}$ & 2 & Filhos \\
\hline Entrevistada 2 & 45 & Negra & $\begin{array}{l}\text { Ensino Méd. } \\
\text { Completo }\end{array}$ & Casada & Cristã & $\begin{array}{c}\text { Dona de } \\
\text { casa }\end{array}$ & 1 & Marido e filho \\
\hline Entrevistada 3 & 40 & Branca & $\begin{array}{l}\text { Ensino Fund. } \\
\text { Incompleto }\end{array}$ & Casada & Cristã & $\begin{array}{c}\text { Dona de } \\
\text { casa }\end{array}$ & 2 & Pais e filho \\
\hline Entrevistada 4 & 50 & Parda & $\begin{array}{c}\text { Ensino Méd. } \\
\text { Completo }\end{array}$ & Solteira & Evangélica & ACS & 2 & Filho \\
\hline Entrevistada 5 & 40 & Parda & $\begin{array}{c}\text { Ensino Méd. } \\
\text { Completo }\end{array}$ & Casada & Cristã & Costureira & 1 & Marido e filho \\
\hline Entrevistada 6 & 33 & Parda & $\begin{array}{l}\text { Ensino Fund. } \\
\text { Completo }\end{array}$ & Casada & Evangélica & $\begin{array}{c}\text { Dona de } \\
\text { casa }\end{array}$ & 4 & Marido e filhos \\
\hline Entrevistada 7 & 31 & Negra & $\begin{array}{l}\text { Ensino Fund. } \\
\text { Incompleto }\end{array}$ & Solteira & Católica & $\begin{array}{c}\text { Dona de } \\
\text { casa }\end{array}$ & 1 & Filha \\
\hline Entrevistada 8 & 35 & Branca & $\begin{array}{l}\text { Ensino Sup. } \\
\text { Incompleto }\end{array}$ & Solteira & Cristã & $\begin{array}{c}\text { Dona de } \\
\text { casa }\end{array}$ & 2 & Marido e filhos \\
\hline Entrevistada 9 & 31 & Branca & $\begin{array}{l}\text { Ensino Sup. } \\
\text { Completo }\end{array}$ & Solteira & Católica & $\begin{array}{l}\text { Assistente } \\
\text { Social }\end{array}$ & 1 & Filho \\
\hline
\end{tabular}

Legenda: $\mathrm{ACS}=$ Agente Comunitário de Saúde

Fonte: Araújo JC, et al., 2019.

\section{Do (des) conhecimento do autismo ao diagnóstico}

Os sinais de alteração do desenvolvimento cognitivo das crianças autistas é o primeiro indício que impulsiona os pais a procurarem ajuda a algum profissional, no intuito de saber ou questionar 0 comportamento do filho, e assim, a confirmação do diagnóstico acontecer (ZANON RB, et al., 2014). Algumas 
mães não tinham nenhum conhecimento sobre o autismo, o que acabara mascarando a identificação das manifestações/sinais clínicos do autismo, não cogitando a existência do autismo, justamente pela falta de conhecimento/informação.

Eu não conhecia o autismo, eu vim conhecer depois do diagnóstico do meu filho (Entrevistada 1)

Antes era totalmente desconhecido para mim, já tinha ouvido umas 2 vezes que foi quando eu me interessei (Entrevistada 2)

E assim, formavam possibilidades causais dos comportamentos dos seus filhos, como por exemplo: o ambiente, condições individuais das crianças ou até deficiências no processo gestacional ou educação dada.

Eu achava que era porque ela era criada só com adultos, não tinha criança por perto e nunca tinha tido a escola (Entrevistada 8)

É uma coisa que eu me pergunto se foi na gravidez, se o problema é no DNA dele, se o problema foi meu, ou do pai dele [...] Eu mesmo já perguntei a psicóloga, a psicopedagoga, e uma delas até falou que poderia ter sido na gravidez, pelos traumas que eu sofri na gravidez (Entrevistada 6)

É natural que as mães queiram uma resposta de por que seu filho tem autismo; entretanto, o autismo ainda não possui uma etiologia claramente elucidada e comprovada, o que compromete a percepção das mães sobre este agravo (JOZÉFCZUK J, et al., 2017).

Houve relato de apenas uma mãe de possuir conhecimento prévio sobre o autismo, mesmo que estereotipado e/ou deturpado, dificultando que esta identificasse precocemente sinais autísticos em seu filho.

Antes falavam que o autista era uma pessoa que se isolava, então essa era a primeira característica que eu sabia [...] ele não se isola, ele interage, então para perceber o autismo nele, foi bem difícil, foram detalhes (Entrevistada 4)

Já outra mãe, como Entrevista 9, havia um conhecimento superficial sobre o agravo, o que notadamente, otimizou a busca por um profissional e confirmação do diagnóstico mais brevemente, relatando:

Bom, eu conheci o autismo na teoria, pela questão da faculdade. Mas você viver isso na prática, é completamente diferente, é outro mundo, é muita coisa. (Entrevistada 9)

Foi percebido que os pais com nível superior tinham acesso melhor à informação, otimizando a identificação mais eficaz dos sinais e, por conseguinte, favorecendo um diagnóstico mais precoce entre as crianças (MAIA FA, et al., 2019).

As mães tiveram papel fundamental para o diagnóstico das crianças, onde as mesmas tiveram a percepção sobre os primeiros sinais ao observar que seus filhos possuíam comportamentos vistos como "diferentes". Há importância da participação dos pais no processo diagnóstico das crianças, que começa na buscar por um auxílio e finaliza com a confirmação diagnóstica (ONZI FZ e GOMES RF, 2015).

Nós de dentro de casa percebemos que ele tinha alguma dificuldade em relação ao falar, porque com 2 anos, ele só falava papai e mamãe (Entrevistada 4).

Nesse sentido, há variabilidade de nível de comprometimento, tanto no âmbito intelectual, interativo ou social. Essa variabilidade é adaptável ao ambiente em que a criança vive e aos estímulos que lhe são ofertados (FIALHO JPG, et al., 2015). Um dos aspectos percebidos pela maioria das mães no foi a dificuldade da verbalização, onde as mães buscavam iniciar um diálogo com o filho ou até mesmo estimular a alguma atividade; porém, sem êxito.

Os autistas além de apresentarem um desenvolvimento tardio da fala, quando iniciam a prática, tendem a ecolalia, ou seja, a repetição das palavras/frases já ouvidas, podendo usar a mesma entonação ou não. 
Você quer ter uma comunicação com ele e você não consegue, você quer ter aquela resposta rápida e você não consegue (Entrevistada 9).

Ele não falava até os 5 anos, ele gesticulava muito, ele me trazia até o que ele queria, me mostrava (Entrevistada 6).

A falta de interação/atenção também foi um ponto predominante nos relatos das mães, sendo configurado como um fator dificultoso na rotina com as crianças.

Você tenta interagir, ele olha para outras coisas, mas não olha pra você (Entrevistada 9).

Também foi relatado o comprometimento da interação com outras crianças, onde o processo de socialização das crianças através de brincadeiras lúdicas mostra-se pouco produtivo (CALEGARI T, et al., 2018). Isso acontece em virtude do déficit social/interativo, sendo necessária, iniciativa por parte das outras crianças.

A questão de você colocar ele com outras crianças, você vê que ele pega o brinquedo na mão da criança, mas não brinca com ela, não tem aquela socialização (Entrevistada 9).

A esfera escolar apresenta diversos desafios na comunicação/socialização para essa criança. A problemática limita-se ao contato com as pessoas (fato explicado pela inabilidade afetiva), pois, as crianças com TEA apresentam fixação em objetos/brinquedos, principalmente aqueles que possuem movimentos giratórios, por exemplo.

Só brincava com aquele carrinho, e não brincava normal, ele coloca pra cima, só pra vê as rodas girando (...) coisa de roda, tudo ele gosta. Pegava o CD ficava rodando, até cair, e pegava de novo, girava e se eu deixasse, ficava o dia todo (Entrevistada 1).

No âmbito das relações com as genitoras, também foi citado os impulsos agressivos por uma das mães participantes. Nesse sentido, as crianças com TEA lançam mão de agressividade em casos de represália/hostilidade a mudanças na rotina ou quando contrariado, por possuírem por hábitos padronizados (ROCHA CC, et al., 2019).

Ele oscila muito. Tá bem e de repente, do nada, ele muda o comportamento. O fato, por exemplo: eu não almoçar, ele já muda. O caminho de comprar o pão, se eu mudar, ele muda. E ele muda do nada e bate, e a gente não sabe o que é, porque ele não fala (Entrevistada 4).

O diagnóstico é um momento de impacto, pois causa diversas modificações no contexto familiar, como a transfiguração das crianças com um adoecimento crônico, alterações na rotina da família, adaptação de papéis, além das consequências em nível social e financeiro (PINTO RNM, et al., 2016). A família e, principalmente as mães cuidadores, vivem um processo de negação, luto e falta de perspectiva com relação ao desenvolvimento da criança.

Quando eu recebi o diagnóstico, eu passei uma fase de 6-7 meses sem aceitar, eu dizia: "meu filho não tem isso, meu filho é normal", é só 'mal criação' dele (Entrevistada 6).

Um ponto que muda todo o processo de aceitação, adaptações, mudanças de rotina e relação mãe e filho é a concepção que as mesmas possuem sobre o autismo, e quando questionadas sobre a sua percepção, as mães relataram:

Não é uma doença, eu entendo como um modo de vida, que a vida... o mundo dele é um pouco diferente da nossa realidade. Eu entendo como as meninas (referindo-se à psicóloga e psicopedagoga do serviço) me explicaram que é um barbante (que é a vida) com vários nózinhos, meu filho tem vários desses nós (Entrevistada 5). 
Certamente, a experiência de ter um filho com autismo corrobora em uma vivência mais difícil quando comparada a outras mães de filhos sem morbidades, exemplificada pela adversidade do contexto como um empecilho para a vida profissional e barreira na relação mãe e filho (SILVA MEA, et al., 2017). Assim, a partir do diagnóstico, as mães e as famílias passam por mudanças rotineiras e reflexões sobre o seu "cuidar", visando sempre a aquisição do conhecimento sobre o agravo, bem como, o repensar de estratégias para melhor acompanhar e intervir no processo de aprendizagem e interação dos seus filhos.

\section{Cuidados ao filho autista: rotina e sobrecarga materna.}

O primeiro desafio vivido pelas mães de crianças autistas se dá com a confirmação do diagnóstico e transfiguração da idealização de uma criança "perfeita" tão sonhada. Por isso, ao passo em que as mães se deparam com a nova realidade, vivem diariamente lutas internas para aceitarem e repensaram o seu papel de mãe.

É bastante difícil, porque primeiro, nenhuma mãe espera ter um filho fora dos padrões (Entrevistada 4).

Cuidar dele é difícil, muito difícil [...] porque você espera um filho, uma criança como outra qualquer. Você vê outras crianças conversando, tagarelando e você quer que seu filho seja daquele jeito né (Entrevistada 9).

Percebe-se como essas mães vivenciam uma perda de expectativas depositadas na criança e quando a criança nasce com alguma limitação significante, a frustação compromete a percepção da mãe para com aquele filho (FERREIRA M, et al., 2018).

A rotina de uma mãe de um autista, o cuidado é a prioridade na vida dessa mulher, dedicando-se integralmente aquele filho, comprometendo assim a sua vida social, afetiva, e profissional, ao passo que não possível exercer atividades fora de casa.

Por isso que hoje eu tô desempregada, não tô empregada porque não tem quem tome conta, entendeu? (Entrevistada 7)

A alta demanda de cuidados compromete estudos, trabalhos, carreira, lazer e atividades diárias, além de quê nem sempre as mães possuem algum tipo de apoio.

A alimentação surgiu nos relatos como uma preocupação comum entre as mães, onde as mães tentavam implantar um hábito de alimentação saudável nos filhos, com presença de muitas frutas, sem alimentos industrializados com grande quantidade de açúcar.

Eu tenho muito cuidado na parte da alimentação, não sou de dar biscoitos recheados, refrigerante não, muita fruta, quando estou na rua um bolinho, um doce (Entrevistada 8).

A alimentação da criança autista é marcada por três respostas principais: seletividade, recusa e indisciplina. Nesse sentido, foi presente no relato de uma das mães a seletividade alimentar da criança autista. Essa condição caracteriza-se pela pouca variedade de alimentos aceitos pela criança, dificultando a ingestão de alimentos com propriedades distintas, favorecendo, assim, a carência nutricional (FERREIRA M, et al., 2018).

Só gosta mesmo de macarrão, se eu der macarrão todo dia, ele come. Quando ele gosta de uma coisa, ele só quer ficar naquilo (Entrevistada 1).

Essas restrições alimentares podem levar a diferentes carências nutricionais, as quais afetam diretamente os padrões de crescimento da criança, ao passo que a infância é em uma fase de intensa evolução do crescimento e desenvolvimento. No decorrer do processo de cuidar, as mães se tornam sobrecarregadas com o acúmulo de demandas a serem executadas, o ambiente familiar se torna estressante e a relação com o filho é prejudicada. 
É cansativo. Porque ele é muito agitado, e quando não dá uma coisa, aí que ele fica mais agitado ainda, morde, bate (Entrevistada 3)

Às vezes a gente se sente cansada. Porque eles têm muita birra, choram muito, ele não gosta de esperar, ele é muito traquino, ele quebra tudo (mesmo na brincadeira) (Entrevistada 2)

A sobrecarga materna é um processo muito comum nas rotinas dessas mães, onde passa a determinar suas vontades, deveres e sentimentos diante da rotina e evolução do filho, independente da configuração familiar, sendo potencializado quando não há companheiros residentes na mesma casa, fazendo com o que todas as atribuições circundem a mãe (FERREIRA M, et al., 2018).

Isso reafirma o fato da mulher como sujeito responsável pela atenção a saúde dos filhos, e assim, percebese que essa trajetória não deve ser trilhada só pela mãe. Essas mães necessitam de um suporte, tanto do parceiro (a), família ou sociedade para manutenção do cuidado dessa criança (FERREIRA M, et al., 2018).

\section{Rede de suporte ou exclusão social?}

Rede de suporte social é uma interligação entre elementos sociais (família, serviços de saúde, instituições) que o indivíduo tem para enfrentar algum agravo, possibilitando o doente a ter condições melhores de vida (ROCHA CC, et al., 2019). Essa rede exerce função primordial na linha de cuidado e evolução do aspecto social-interativo de uma criança autista, tendo em vista a importância que os indivíduos exercem sobre a construção da sociabilidade dessa criança.

A família do pai dele também não aceita, estão começando a aceitar agora, de uns 2 anos pra cá (Entrevistada 6).

Os familiares apresentam dificuldades em lidar com a situação, desequilibrando a dinâmica familiar, a percepção dos pais sobre a criança e da criança consigo mesma, caso essa situação seja estendida por toda a primeira infância (MAIA FILHO ALM, et al., 2016).

Por isso, é comum que entre o ambiente familiar, as mães se apresentem como o centro do cuidado que essas crianças possuem, uma vez que outras pessoas não se sintam inseridas nesse contexto do cuidado. Nesse sentido, é natural desenvolver uma rotina com sobrecarga materna, sendo a mãe, a única responsável por manter os cuidados diários a esta criança, sacrificando a sua rotina, sua vida profissional e pessoal.

Só às vezes que é trabalhoso, ainda mais eu que sou sozinha, não tem o pai dele pra ajudar sabe? (Entrevistada 3)

Só Deus! É só eu e ele mesmo, no dia-a-dia, dentro de casa é só eu e ele (...) no dia-a-dia, na educação, no banho, é tudo eu (Entrevistada 9).

Isso predispõe essas mulheres a altos níveis de estresse, corroborando em agravos na saúde física e psicológica. Alguns outros fatores podem contribuir para o desenvolvimento de doenças, como a falta de apoio conjugal, a quantidade de demandas dos filhos, a falta de apoio familiar e o isolamento social (MAIA FILHO ALM, et al., 2016).

Em outros relatos, foram apontados a ajuda dos pais (das crianças) no cuidado, sendo o único apoio que essas mães tinham para acionar.

\section{O pai. Só eu e o pai (Entrevistada 5). \\ O pai dele me ajuda (Entrevistada 1).}

A figura paterna se mostra de extrema importância no contexto, tanto pela questão do apoio emocional à mãe, como também sendo um grande portador de vínculo e interação entre a criança, fazendo-a desenvolver habilidades sociais durante o convívio (LOURETO GDL e MORENO SIR, 2016).

O ambiente escolar apresenta-se com diversas variáveis existentes na inserção da criança autista, a exemplo: preparo profissional, integração destes com os pais e receptividade das outras crianças. Para isso, 
é fundamental que os professores estejam preparados para manejar o processo pedagógico dessa criança. Nesse contexto é comum a aplicação de julgamentos sobre a criança e até à própria mãe, diante do pouco conhecimento.

Quando uma pessoa vê uma criança em crise, pensa que a criança é birrenta, é mimada, é estragada, não entende (Entrevistada 9).

Os comentários dos outros sobre a criança autista atingem diretamente a mãe, onde ela reafirma para si a importância da sua proteção ao filho diante do incômodo sentido pelas outras pessoas com a presença da criança (FERREIRA M, et al., 2018). Tal situação traz para os pais uma preocupação contínua, onde os filhos são rejeitados e minorizados a um agravo e que sua condição especial se transforma em impossibilidade de manter relações estáveis com as outras pessoas.

A exclusão social vivida pelas crianças autistas e percebidas pelos pais, causam profundo estresse emocional para aquela família, ao passo de se sentirem excluídas completamente da sociedade, uma vez que a criança - centro da família - é excluída, configurando um fator potencial de adoecimento mental (RIOS CC e KENNETH R, 2019).

\section{CONCLUSÃO}

Nota-se que o autismo precisa ser discutido em diferentes espaços e contextos, para fornecer amplas informações para a população, desmistificando estereótipos, mostrando possibilidades terapêuticas e ressaltando a capacidade de vida dos autistas. É necessária uma compreensão de que as condições do agravo não incapacitam os autistas, apenas requerem uma reformulação de métodos para a realização das atividades. Ainda, percebe-se a lacuna de estudos para aspectos tão variados do transtorno do espectro autista, necessitando de uma abordagem sistemática sobre este agravo.

\section{REFERÊNCIAS}

1. BRASIL. Ministério da Saúde. Secretaria de Atenção à Saúde. Departamento de Ações Programáticas Estratégicas. Diretrizes de Atenção à Reabilitação da Pessoa com Transtornos do Espectro do Autismo (TEA). Ministério da Saúde, Secretaria de Atenção à Saúde, Departamento de Ações Programáticas Estratégicas. Brasília: Ministério da Saúde, 2014.

2. CALEGARI T, et al. A criança autista em sessão de brinquedoterapêutico dramático: uma análise winnicottiana. Rev. Soc. Bras. Enferm. Ped. 2018; 18(1): 43-8.

3. FERREIRA M, SMEHA LN. A experiência de ser mãe de um filho com autismo no contexto da monoparentalidade. Psicologia em Revista. 2018; 24(2): 462-481.

4. FIALHO JPG, et al. Produção de variabilidade comportamental e sua extensão em crianças com autismo. Acta Comportamentalia. 2015; 23(4): 391-404.

5. GOMES PTM, et al. Autismo no Brasil, desafios familiares e estratégias de superação: revisão sistemática. J. Pediatr. 2015; $91(2): 111-121$.

6. AUTISMO EM MENINOS: entenda porque eles são os mais afetados. 2018. In: Instituto Lico Kaesemodel.

7. JÓZEFCZUK J, et al. Homocysteine as a Diagnostic and Etiopathogenic Factor in Children with Autism Spectrum Disorder. Journalof Medicinal Food. 2017; 20(8).

8. LOURETO GDL, MORENO SIR. As relações fraternas no contexto do autismo: estudo descritivo. Rev. Psicopedagogia. 2016; 33(102): 307-18.

9. LYALL K, et al. Maternal lifestyle and environmental risk factors for autism spectrum disorders. Int J Epidemiol. $2014 ; 43(2): 443-64$.

10. MAIA FA, et al. Transtorno do espectro do autismo e idade dos genitores: estudo de caso-controle no Brasil. Cad. Saúde Pública. 2018; 4(8): e00109917.

11. MAIA FA, et al. Importância do acolhimento de pais que tiveram diagnóstico do transtorno do espectro do autismo de um filho. Cad. saúde colet. 2016; 24(2): 228-234.

12. MAIA FILHO ALM, et al. A importância da família no cuidado da criança autista. Rev. Saúde em Foco. 2016; 3(1): 66-83.

13. MINAYO MCS. O desafio do conhecimento. 13. ed. São Paulo: HUCITEC, 2013. 
14. MISQUIATTI ARN, et al. Sobrecarga familiar e crianças com transtorno do espectro do autismo: perspectivas dos cuidadores. Rev. CEFAC. 2015; 17(1): 192-200.

15. ONZI FZ, GOMES RF. Transtorno do Espectro Autista: a Importância do diagnóstico e reabilitação. Caderno pedagógico. 2015; 12(3): 188-199.

16. PINTO RNM, et al. Autismo infantil: impacto do diagnóstico e repercussões nas relações familiares. Rev Gaúcha Enferm. 2016; 37(3): 615-72.

17. RIOS CC, KENNETH R. Especialismo, especificidade e identidade - as controvérsias em torno do autismo no SUS. Ciência \& Saúde Coletiva. 2019; 24(3): 1111-1120.

18. ROCHA CC, et al. Autismo associado à epilepsia: relato de caso. Revista Eletrônica Acervo Saúde. 2019; 20(20).

19. SEMENSATO MR, et al. Grupo de familiares de pessoas com autismo: relatos de experiência parentais. Aletheia. 2010; 32: 183-194.

20. SILVA MEA, et al. Rede e Apoio Social na doença crônica infantil: compreendendo a percepção da criança. Texto Contexto Enferm. 2017; 26(1).

21. ZANON RB, et al. Identificação dos Primeiros Sintomas do Autismo pelos Pais. Psicologia: Teoria e Pesquisa. Porto Alegre, 2014; 30(1): 25-33. 